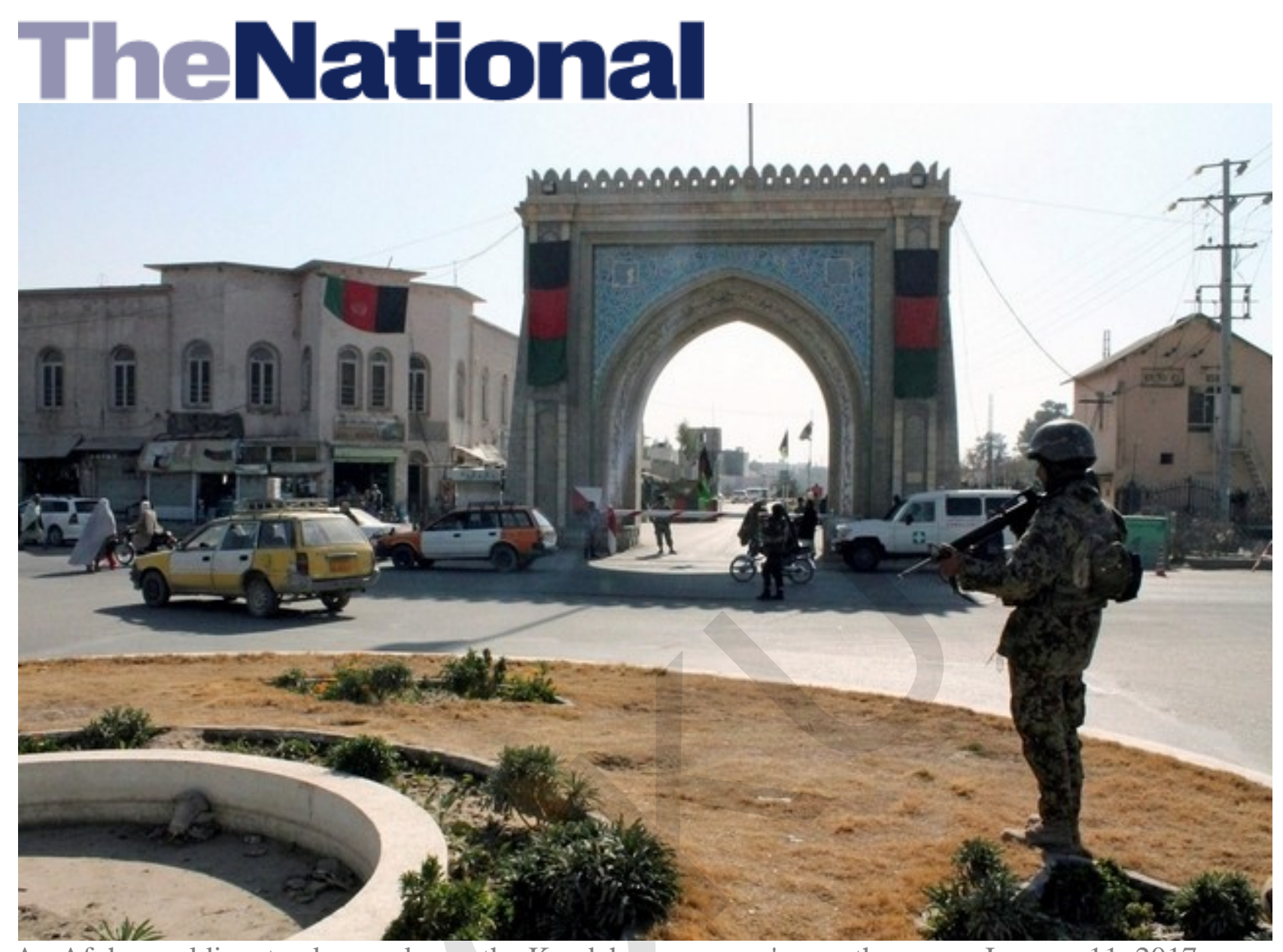

An Afghan soldier stands guard near the Kandahar governor's guesthouse on January 11, 2017, where a bomb blast killed five Emiratis and at least seven others, including Hashim Karzai. Ahamad Nadeem/Reuters

\title{
Cousin of Hamid Karzai dies of injuries suffered in Kandahar attack
}

$\underline{\text { Fazelminallah Qazizai }}$

January 16, 2017 Updated: January 16, 2017 11:24 PM

$\frac{\bullet}{\bullet}$

$\underline{\text { Related }}$ 


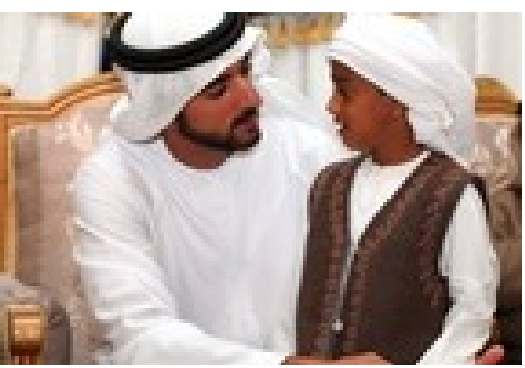

- UAE leaders continue to offer condolences to families of those killed in Kandahar bombing

- Hundreds turn out for funerals of Emiratis killed in Afghanistan terror attack - in pictures

- $\quad$ Did ISIL, the Taliban or the Haqqani Network carry out the Kandahar attack?

- UAE ambassador returns home for treatment after bombing in Kandahar

- Five Emiratis killed in Afghanistan attack

Topics:

- Afghanistan

Kabul // An Afghan businessman died on Monday from injuries suffered in the Kandahar bomb attack that killed five Emiratis.

Hashim Karzai, cousin of former president Hamid Karzai, died in hospital in India, where he had been sent for treatment after slipping into a coma, his brother Haji Karzai told The National.

He was injured when explosives placed under a sofa went off as the Kandahar governor was entertaining a UAE delegation at his guesthouse last Tuesday. Eleven others were killed in the blast.

The UAE Ambassador to Afghanistan Juma Al Kaabi was injured in the attack and flown back to Abu Dhabi aboard a military plane on Thursday to receive further treatment. The governor of Kandahar, Homayun Azizi, was also injured.

Hashim Karzai, 58, was the head of a construction company building a new town in Kandahar and had donated land for the UAE-funded Khalifa bin Zayed Al Nahyan orphanage for which the ambassador laid the foundation stone on the day of the bombing.

He is survived by his wife and three children. His funeral will take place in the United States, where he was living before going to work on the Kandahar project, said his brother, who lives in Kandahar.

The Afghan government blamed the Taliban for the attack. But the group denied any involvement despite admitting to attacks in Helmand and Kabul on the same day. 